\title{
Studies of internal stress induced by solidification of menthol melt as temporary consolidant in archaeological excavations using resistance strain gauge method
}

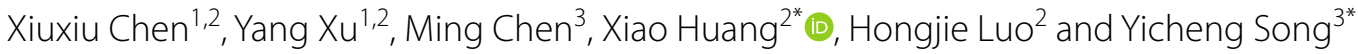

\begin{abstract}
Volatile organic solids, such as cyclododecane or menthol, have been employed as temporary reinforcement material during archaeological excavations. They are usually applied as melts and reinforcement is achieved once the melts solidify. Such solidification process can induce internal stress on the artifacts, which can be a big concern, especially to those very precious and fragile ones. However, information about such stress is still extremely limited at present. This paper proposes an experimental method based on resistance strain gauge technique to monitor the deformation induced by solidification of menthol melt. Bending tests are performed on very thin glass slides. The solidification process of menthol melt is well characterized by the development of mechanical strains. Then, menthol melts are applied to three kinds of simulated samples, i.e. glass, sandstone and rice paper, to investigate the mechanical response of preserved bodies upon solidification. It is found that menthol melt will generate certain amount expansion or contraction of the objects upon solidification. The stresses induced, evaluated according to obtained strains, are generally quite small, indicating that application of menthol as reinforcement material is safe in mechanics for cultural relics.
\end{abstract}

Keywords: Menthol, Temporary consolidation, Archaeological excavation, Internal stress

\section{Introduction}

At archaeological excavation sites, on-site consolidation is an important and widely applied conservation technique. Inorganic materials such as plaster [1-5] as well as organic synthetic polymers such as polyurethanes [6-9], polyacrylates $[10,11]$ and epoxy resins $[12,13]$ are all used to consolidate cultural relics on-site. However, application of these materials are subjected to an obvious drawback that they are very difficult, sometimes even impossible, to be removed afterwards. This would

\footnotetext{
*Correspondence: xhuang@shu.edu.cn; ycsong@shu.edu.cn

${ }^{2}$ Institute for the Conservation of Cultural Heritage, Shanghai University,

Shanghai 200444, China

${ }^{3}$ School of Mechanics and Engineering Science, Shanghai University,

Shanghai 200444, China

Full list of author information is available at the end of the article
}

bring some negative effects on following archaeological research and conservation work.

Recently, on-site temporary consolidation has attracted more and more attention due to its reversibility. Cyclododecane (CDD) [14-21] and menthol [22-25], also referred as "volatile binder media" [23, 24], are mostly used temporary consolidants. In typical applications, the material is melted and applied on the target cultural relics. And then, the consolidated relics can be transported safely to museums or laboratories, where the consolidants can be completely removed easily via sublimation. Residue free is the most popular character of this temporary consolidation technique, since there is no consolidation molecules left to interfere with future archaeological research and conservation work. Detailed application procedures are provided elsewhere in literature [16, 21, 23].
Springer Open

(c) The Author(s) 2020. This article is licensed under a Creative Commons Attribution 4.0 International License, which permits use, sharing. adaptation, distribution and reproduction in any medium or format, as long as you give appropriate credit to the original author(s) and the source, provide a link to the Creative Commons licence, and indicate if changes were made. The images or other third party material in this article are included in the article's Creative Commons licence, unless indicated otherwise in a credit line to the material. If material is not included in the article's Creative Commons licence and your intended use is not permitted by statutory regulation or exceeds the permitted use, you will need to obtain permission directly from the copyright holder. To view a copy of this licence, visit http://creativeco mmons.org/licenses/by/4.0/. The Creative Commons Public Domain Dedication waiver (http://creativecommons.org/publicdomain/ zero/1.0/ applies to the data made available in this article, unless otherwise stated in a credit line to the data. 
Internal stress can be induced by solidification of an organic melt due to factors such as volumetric shrinkage, thermal stress etc. [26, 27]. Internal stress is one of the most common reasons for material failures [27]. Thus, it arouses our attention and interest in investigating possible internal stress induced on the artifacts during temporary consolidation practice. Although successful applications of CDD and menthol as consolidant have demonstrated their safety to cultural heritages [14-25], vital information about the internal stress such as generation mechanism, magnitude and distribution, which can be interesting and helpful to conservators, is still unclear.

Internal stress is very difficult to observe, recognize and measure directly. Many indirect methods have been invented and developed to measure internal stress of different types and forms of materials [28-35]. Among these methods, resistance strain gauge [33-35] is a commonly used strain measurement device. Its working principle is that the electrical resistance of its metal part changes linearly with its deformation [36]. Resistance strain gauge method has been widely used in measuring the internal stress of railways [37], bridges [38], building constructions [39], reinforced concrete components [40] etc. Plenty of applications have shown that resistance strain gauge measurement is a fast, sensitive, accurate and reliable method. Meanwhile, the measurement does not change the original stress state of test objects.

In this paper, resistance strain gauge measurement method is introduced into the study of internal stress induced by solidification of menthol melts. Three different simulated samples, i.e. sandstone, glass and rice paper, are chosen to simulate the materials usually found in archaeological excavations. Information of such internal stresses about its generation mechanism, distribution and magnitude is revealed for the first time.

\section{Experimental \\ Materials}

L-menthol (99\%, melting point $43{ }^{\circ} \mathrm{C}$; see Fig. 1) is purchased from Aldrich Co., used as received. The substrates used for internal stress experiments are commercial glass (glass I: $18 \mathrm{~mm} \times 18 \mathrm{~mm} \times 0.12 \mathrm{~mm}$; glass II: $25 \mathrm{~mm} \times 75 \mathrm{~mm} \times 1 \mathrm{~mm}$ ), sandstone from Yungang Grottos (size: $25 \mathrm{~mm} \times 75 \mathrm{~mm} \times 2 \mathrm{~mm}$ ) and commercial rice paper (size: $25 \mathrm{~mm} \times 75 \mathrm{~mm} \times 0.01 \mathrm{~mm}$ ). The Yungang sandstone used has a porosity of $6.93 \%$ and median pore size of $505 \mathrm{~nm}$ based on MIP measurement. Pictures of the substrates and MIP results can be found in the Additional file 1.

\section{Instrumentation}

The elastic moduli of rice paper and sandstone were measured by an electronic universal testing machine

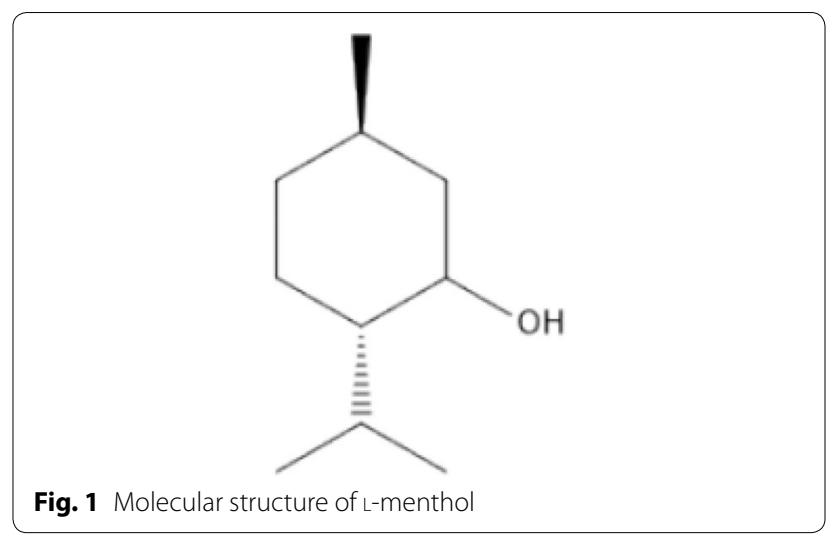

(BZ2.5/TS1S Zwick/Roell, Germany). The elastic modulus of glass was measured by a solid material dynamic elastic property tester (China Building Materials Test and Certification Group Co., Ltd. DST-III).

The strain was measured by a DH3818Y static stress tester (Jiangsu Donghua Testing Technology Co., China). The strain gauges used were model BE120-3AA (Jiangsu Donghua Testing Technology Co., China) with temperature self-compensation function, resistance of $120.1 \pm 0.2 \Omega$ and gauge factor of 2.00-2.20.

As shown in Fig. 2, the strain gauge has layered structure, in which a sensitive grid made of thin metal foil $(2.8 \mathrm{~mm} \times 2.0 \mathrm{~mm})$ is sandwiched between a so-called plastic film $(6.4 \mathrm{~mm} \times 3.5 \mathrm{~mm})$ and a laminated film. Because the resistance of the grid is extremely sensitive to strain changes, very small strain changes, as low as to the order of $10^{-6}$, can be detected. Equation 1 describes the relation between strain changes and resistance changes of the metal coil. Based on Eq. 1, the changes in resistance can be converted to the strain changes.

$$
(\Delta R) / R=K \times \varepsilon
$$

where $R$ strain gauge original resistance in $\Omega$ (ohm); $\Delta R$ resistance change caused by elongation or compression in $\Omega(\mathrm{ohm}) ; K$ gauge factor (2.00-2.20); $\varepsilon$ strain.

\section{Experiment setup}

In this work, a static resistance stress-strain test setup is applied. As static resistance stress-strain test is very sensitive, the experiments are carried out in a separated room and precautions are taken to avoid possible outside disturbances. A quarter bridge circuit is employed for the testing. The strain gauge is self-compensated with temperature, which can reduce the influence of temperature on the resistance of the variable pieces. In order to prevent interference from other electrical appliances on site, shielded wires are used as connecting wires, and the lengths of all wires are kept the same as $30 \mathrm{~cm}$ long to 


\section{Laminated film}

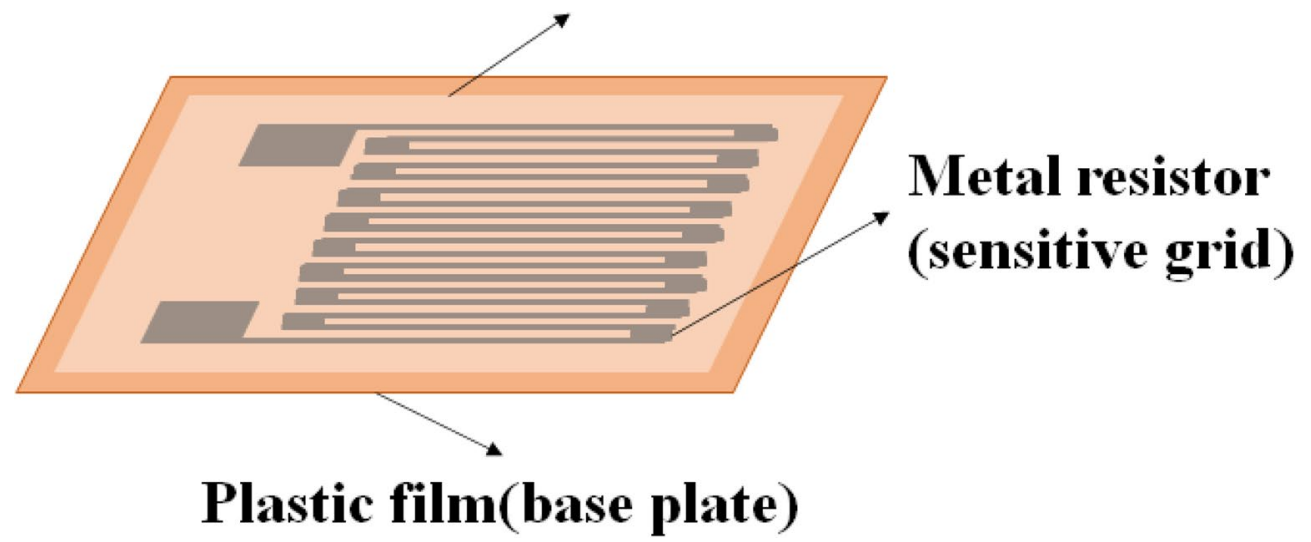

Fig. 2 The schematic of a strain gauge

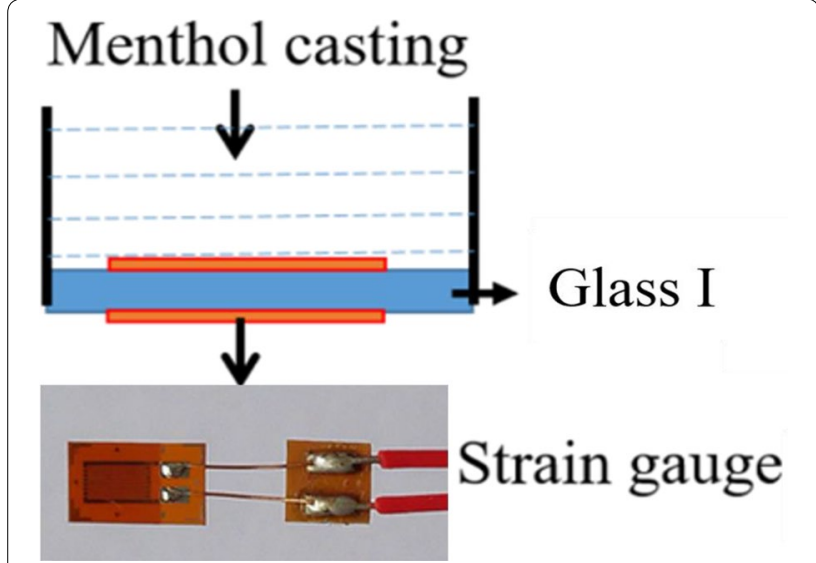

Fig. 3 Schematic of strain tests on glass I sample

reduce the influence of wire resistance. The strain gauges are carefully sealed to be waterproof and moisture-proof.

The whole gauge is firmly glued (ethyl $\alpha$-cyanoacrylates glue) on the testing substrate to ensure that the deformation of substrate can be precisely measured by the sensitive grid. Detailed setup is described below. Each strain gauge experiment is performed at least three times to guarantee the reproducibility. A fresh sample is used each time.

\section{Model sample}

Two strain gauges were glued to the top and bottom of a glass I sample. Because the electric resistance of strain gauge is affected by temperature, very thin glass substrate (0.12 $\mathrm{mm}$ in thickness) was used to minimize the strain difference due to temperature gradient across glass thickness. Vertical plastic tape was wrapped around to build a sink to accommodate the melted menthol, as demonstrated in Fig. 3. Then, 0.1, 0.5, 1, and $2 \mathrm{~mL}$ of menthol melts of 60 or $80{ }^{\circ} \mathrm{C}$ were cast on the samples respectively. Strains were measured and recorded on site during the whole solidification process.

\section{Simulated samples}

The strains were measured for three different simulated materials. In each experiment, two strain gauges were glued at two positions. One position is where menthol melt is applied, and the other position is away from applying position.

\section{Results and discussions}

Static resistance stress-strain tests on model samples

Figure 4 provides the variation of strains and temperature with respect to operation time. It appears that the strain gauge on the top of glass I sample (where melted menthol is applied) provides negative values indicating compression. Meanwhile, the other strain gauge on the bottom of glass provides positive values which suggest tensile deformation. It is known that solidification of menthol melt is accompanied by volumetric shrinkage [24], which leads to concave bending of the glass I sample in the present experiment. This bending results in compression and stretching, respectively, in the upper and lower portion of glass, in consistent with the measurements of strain gauges. Figure 4 also shows that the two strain curves provided by upper and bottom strain gauges are roughly symmetrical about the horizontal axis which indicates zero strain.

Combined with temperature curve, more information can be read from Fig. 4. When menthol melt is just applied, i.e. before $500 \mathrm{~s}$, low level strain noises were 


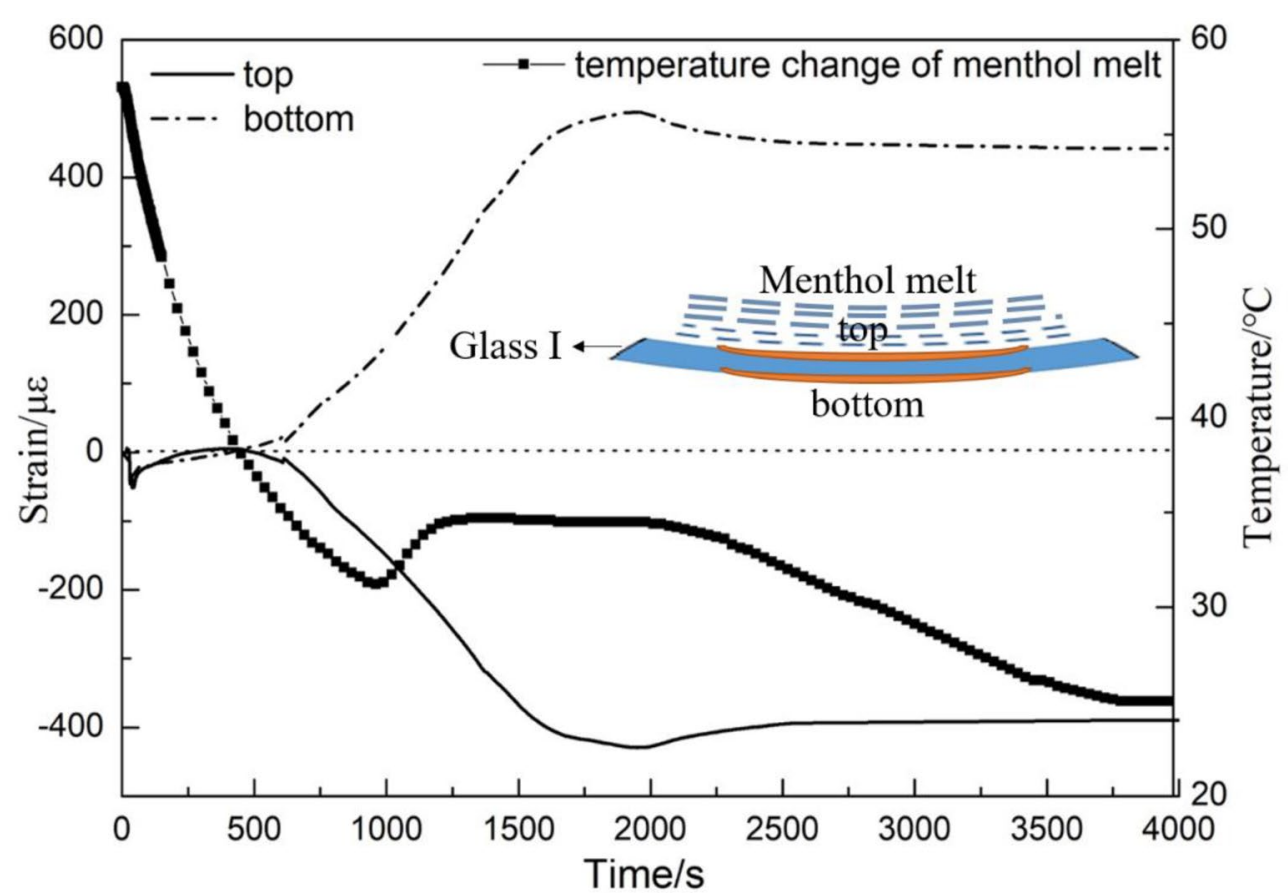

Fig. 4 Results of strain tests on glass I sample $\left(2 \mathrm{~mL} 60^{\circ} \mathrm{C}\right.$ melt applied on an area of $18 \mathrm{~mm} \times 18 \mathrm{~mm}$; thickness is around $\left.10 \mathrm{~mm}\right)$

observed due to thermal impacts. After that, from 500 to $1000 \mathrm{~s}$ is an early stage of solidification. In this stage, temperature decreases below the melting point of menthol and both compressive and tensile strains start to increase, indicating that the volumetric shrinkage of menthol upon solidification starts to lead to bending of glass substrate. From $1000 \mathrm{~s}$ to about $2000 \mathrm{~s}$ is the steady stage of solidification. In this stage, temperature rises again due to exothermic solidification process. When the thermal balance is established between internal heat generation and diffusion to outside ambience, the temperature becomes stable, indicating a stable solidification stage. In this stage, the strains increase with nearly constant gradients, implying that menthol solidifies in a constant rate. Completion of solidification is found around $2000 \mathrm{~s}$, from when the temperature drops again due to termination of exothermic solidification. At the same time, both strains reach peak values and then stop increasing. This verifies the completion of solidification from mechanical view, i.e. menthol stops to shrinkage and, therefore, is unable to cause further bending of glass. The period after $2000 \mathrm{~s}$ is a relaxation stage. In this stage, temperature gradually lowers down showing that no solidification reaction takes place. The strains decrease slightly, probably due to structural relaxation/rearrangement which is often observed in imperfectly crystallized polymers [41].

Figure 4 provides an important insight to the application of menthol for temporary conservation. In real applications, although white waxy solid can be observed just a few minutes after menthol melt is applied, it is still difficult for people to tell whether solidification is completed. Our experiment shows that the solidification of menthol takes much long time than we expected and the solidification achieves peak mechanical strength in about $2000 \mathrm{~s}$. When melted menthol is applied in archaeological excavations, enough time should be given to enable the menthol solidifies completely for a higher strength.

Figure $5 \mathrm{a}, \mathrm{b}$ are prepared to discuss the impacts of menthol quantities and melt temperatures on solidification, respectively. Figure $5 \mathrm{a}$ shows that application of more menthol leads to longer solidification time as well as higher strains. This indicates that stronger stress effects would be induced in applications of large quantities of menthol. Figure $5 \mathrm{~b}$ illustrates that application of menthol melts of higher temperature would enhance the bending deformation of glass substrate and lead to larger strains.

\section{Static resistance stress-strain tests on simulated samples}

Previous studies have characterized the solidification process of menthol using a model sample. In this part we will focus on samples closer to real cases in conservation of cultural relics. Three simulated samples are investigated, i.e. glass II, Yungang sandstone and rice paper, representing rigid non-porous, rigid porous and soft materials, respectively. These are all common materials 

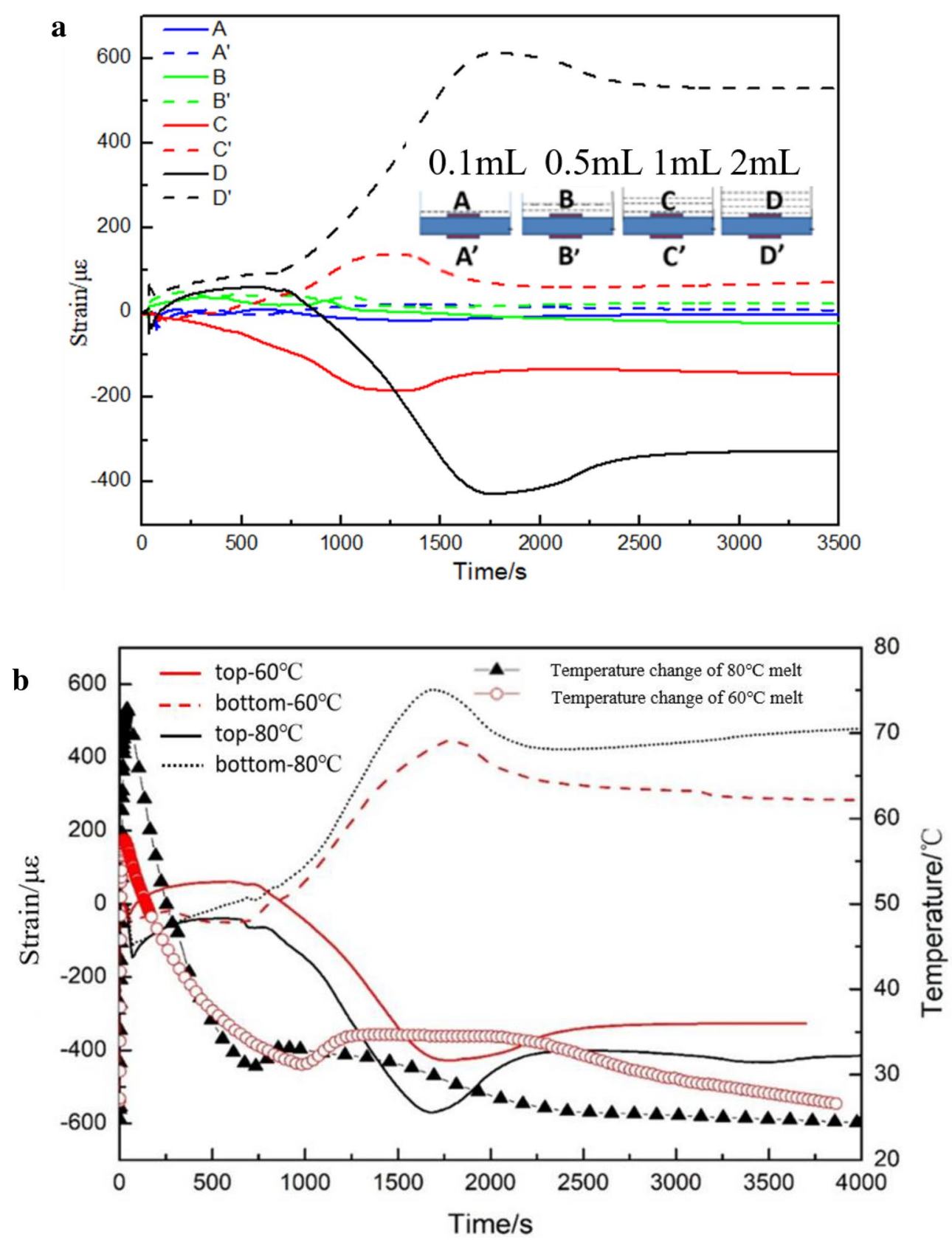

Fig. 5 Results of strain tests on glass I samples with a different amounts of menthol melts, applied on areas of $18 \mathrm{~mm} \times 18 \mathrm{~mm}$; thicknesses are around $1 \mathrm{~mm}, 3 \mathrm{~mm}, 5 \mathrm{~mm}, 10 \mathrm{~mm}$ respectively; $\mathbf{b} 2 \mathrm{~mL}$ menthol melts of 60 or $80^{\circ} \mathrm{C}$, applied on areas of $18 \mathrm{~mm} \times 18 \mathrm{~mm}$; thicknesses are around $10 \mathrm{~mm}$

encountered during excavations. The resistance strain gauges need to be glued on the samples firmly. Thus, for the convenience and practicality of the research work, non-aged simulated samples with relative strong mechanical strength are used. Based on the basic physical understanding of this phenomenon, the occurrence of inner stress should not be related to whether samples are aged or fragile. The outcomes of inner stress are closely related to the status of the samples. So, the results obtained should be applicable to aged or fragile artifacts as found in archaeological excavations.

As demonstrated in Figs. 6, 7 and 8, two strain gauges are pasted on one side of each sample. In order to investigate the comprehensive stress profile induced due 


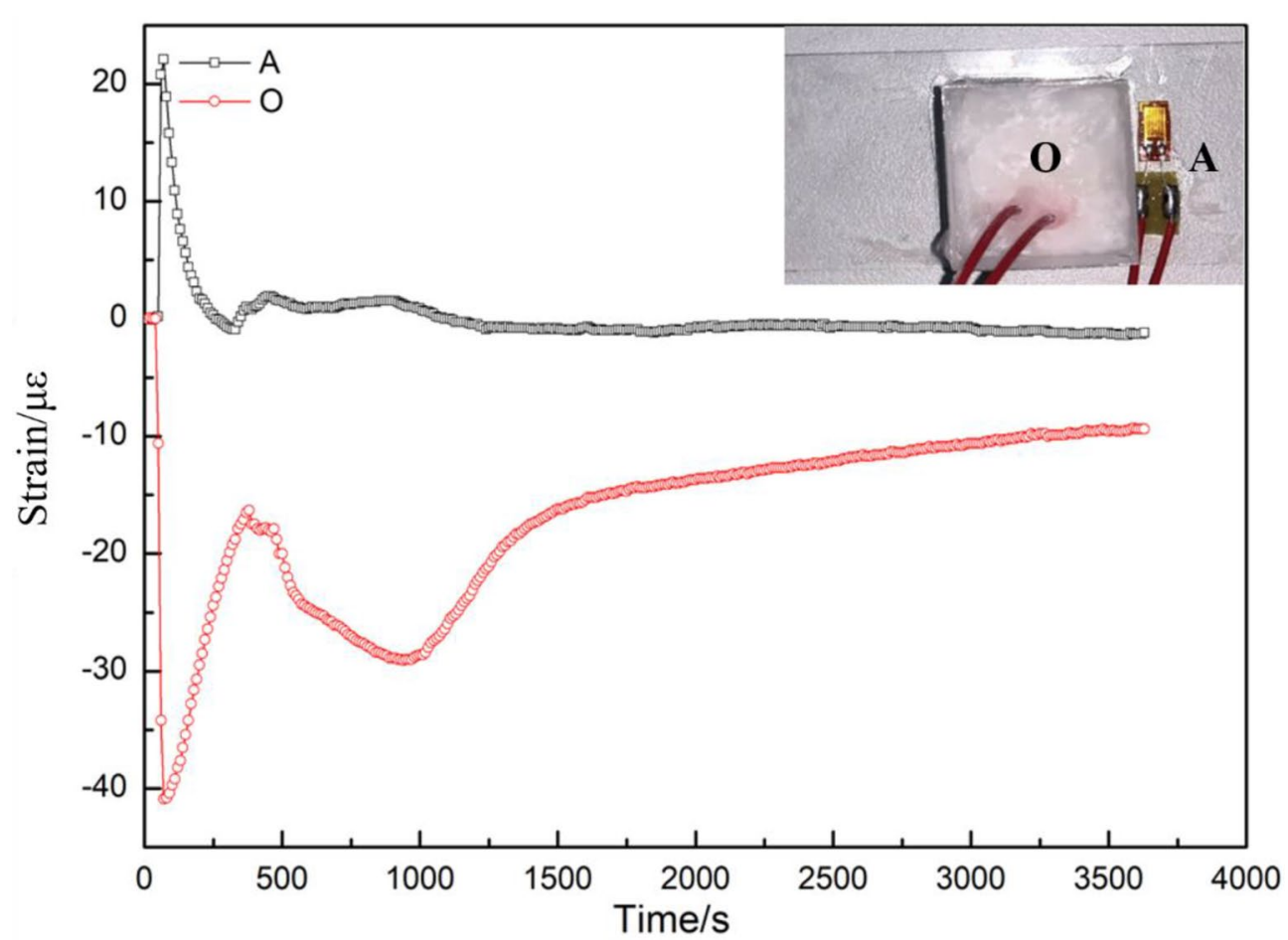

Fig. 6 Results of strain tests on glass II sample $\left(2 \mathrm{~mL} 60{ }^{\circ} \mathrm{C}\right.$ menthol melt applied on an area of $18 \mathrm{~mm} \times 18 \mathrm{~mm}$; thickness is around $\left.10 \mathrm{~mm}\right)$

to menthol application, one gauge denoted by "O" is in the region where menthol melt is applied, the other one denoted by " $\mathrm{A}$ " is away from melt application. Precautions have been taken to prevent outflow of menthol melt.

The results on rigid non-porous glass II samples are shown in Fig. 6. The stain curves are divided into two regions. The first region, from 0 to about $400 \mathrm{~s}$, is an invalid phase as the signals are mainly induced by thermal impact of high temperature melts. After $400 \mathrm{~s}$, increasing strain at position $\mathrm{O}$ is observed, indicating solidification of menthol melt. The negative values indicate compression, in consistent with model sample (glass I). The strain reaches maximum value at around $1000 \mathrm{~s}$, much faster than it does in glass I sample. This is because in glass II case, the melt is cooled down much faster. After $1000 \mathrm{~s}$, the strain starts to gradually decrease due to some degree of structural rearrangement before it stabilizes [41]. For position $\mathrm{A}$, strain just oscillates in a small range around zero strain except the first invalid stage. It indicates that the stress in the region outside menthol application is basically unaffected by the solidification of menthol.

Yungang sandstone, representative of rigid porous material, is also investigated. In Fig. 7a, when menthol melt is applied on position $\mathrm{O}$, strain at the $\mathrm{O}$ changes rapidly due to thermal impact. After that, when the melt starts to solidify, strain at position $O$ switches quickly from negative to positive side, indicating that solidification of menthol melt finally leads to facial stretching of sandstone. This phenomenon may be attributed to the porous microstructure of sandstone. When applied, melted menthol might permeate into the porous sandstone. It is speculated that solidification of menthol inside the micro pores would generates expansion actions on the pore walls, resulting in stretching of sample. The strain of position A is around - 10, indicating weak compressive stress. This is reasonable as the stretching of the small core area has to be balanced by the compression of surrounding area.

In order to verify the proposed mechanism above, two more sets of experiments are carried out on sandstones. As shown in Fig. 6b, four strain gauges, referred as 1 (top), 2 (top), 3 (bottom), and 4 (bottom), are glued on both sides of the sandstone. $2 \mathrm{~mL}$ of menthol melt is applied. It can be seen from the figure that both gauge 1 and 2 provide positive values indicating tensile strain in the upper portion, while gauge 3 and 4 show negative values indicating compressive deformation in the lower portion.

In another test shown in Fig. 7c, much less menthol melt is applied. In this case, variation of strain is a bit similar to that applied on glass. The strain at position $\mathrm{O}$ is always negative. This suggests that the little menthol mainly solidifies on the surface of sandstone instead of 

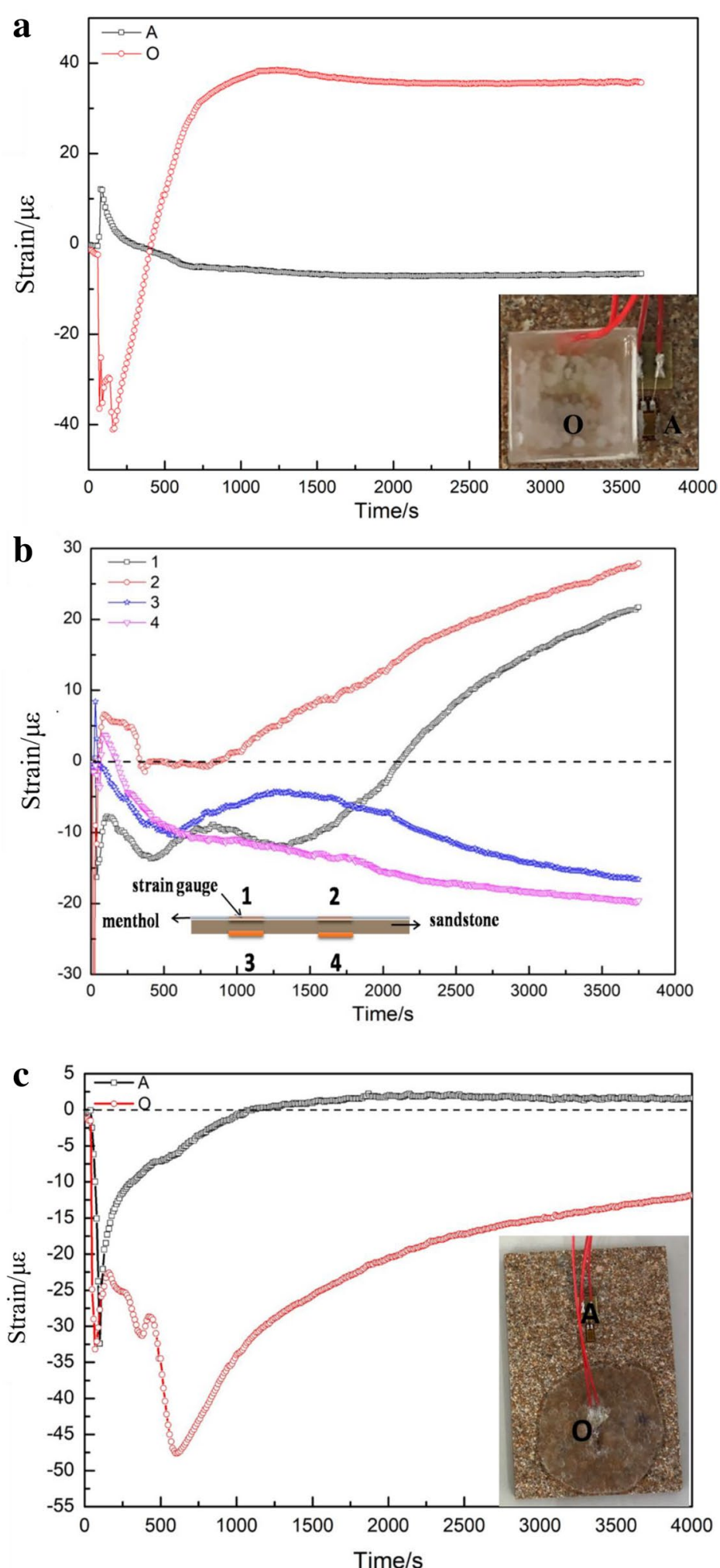

Fig. 7 The strain produced by the solidification of menthol melt $\left(60{ }^{\circ} \mathrm{C}\right)$ on the Yungang sandstones. a 2 strain gauges setup $(2 \mathrm{~mL}$ melt applied on an area of $18 \mathrm{~mm} \times 18 \mathrm{~mm}$, thickness is around $10 \mathrm{~mm}$ ); $\mathbf{b} 4$ strain gauges setup ( $2 \mathrm{~mL}$ melt applied on an area of $25 \mathrm{~mm} \times 75 \mathrm{~mm}$, thickness is around $2 \mathrm{~mm}$ ); 2 strain gauges setup ( $1 \mathrm{~mL}$ melt applied on a larger sandstone sample, applying area is about $60 \mathrm{~mm}$ in diameter and $1 \mathrm{~mm}$ in thickness) 


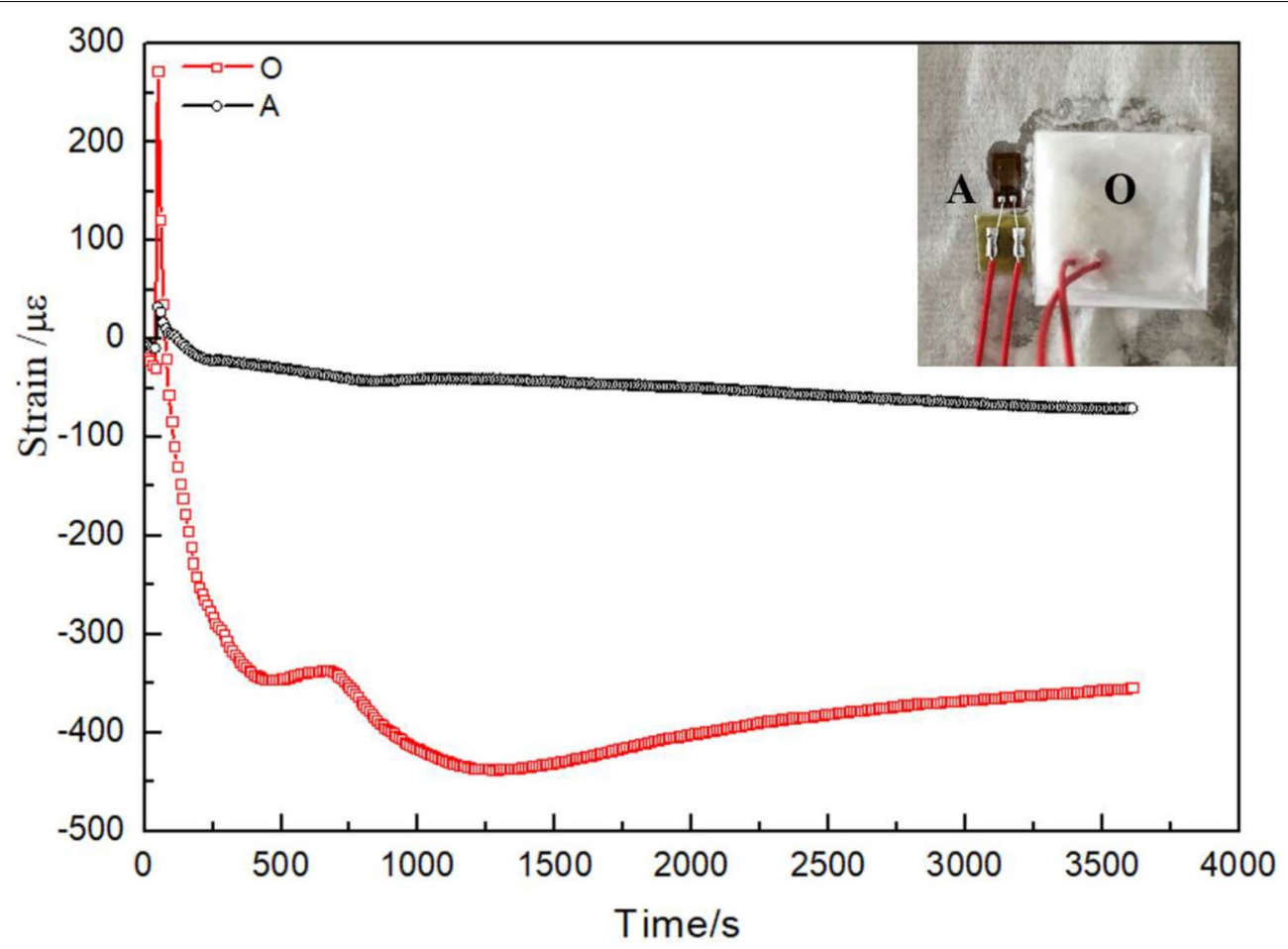

Fig. 8 Results of strain tests on a rice paper $\left(2 \mathrm{~mL} 60{ }^{\circ} \mathrm{C}\right.$ menthol melt applied on an area of $18 \mathrm{~mm} \times 18 \mathrm{~mm}$; thickness is around $10 \mathrm{~mm}$ )

infiltrating into the pores due to fast cooling. The surface deformation is therefore contraction.

Rice paper, representative of soft material, is also tested, as seen in Fig. 8. As paper does not conduct heat well, thermal influence on the strain at position $\mathrm{A}$ is insignificant. It is seen that the strain at position $\mathrm{O}$ stabilizes at $-400 \mu$, which is larger than that of glass II and sandstone. This is because paper is too soft to withstand the contraction of menthol. Unlike rigid samples, the strain at position A of rice paper is also compressive, the same as position $\mathrm{O}$. It suggests that the contraction of the menthol area may lead to contraction in larger neighboring area in soft substrate.

\section{Stress evaluations of solidification of menthol melts on simulated samples}

The information revealed by the static resistance stressstrain tests is the strain of certain media upon solidification of menthol melt. It is quite straight forward according to elastic constitutive that stress strain relation is:

$$
\sigma(\text { stress })=E(\text { Elastic Modulus }) \times \varepsilon(\text { strain }) .
$$

The elastic modulus of glass II sample is acquired to be 71.52 GPa by dynamic elastic modulus measurement method. The elastic moduli of Yungang sandstone and rice paper are 3.08 and $1.12 \mathrm{GPa}$, which are acquired by compression or tensile method on a universal mechanical testing machine respectively. The maximum strain values of point $\mathrm{O}$ (position where menthol melt is applied) in each figure are chosen to calculate the stress. The internal stress induced by menthol melts on glass (Fig. 6), sandstone (Fig. 7a) and rice paper (Fig. 8) is calculated to be $0.71,0.11$ and $0.39 \mathrm{MPa}$, respectively. Although these data might not be very accurate, the order of the magnitudes is acceptable. It shows that all the stresses are quite small. Application of menthol as temporary conservation material is safe to cultural heritages from mechanical viewpoint.

\section{Conclusion}

On-site temporary consolidation becomes more and more popular during archaeological excavations. Consolidation is achieved after consolidant melts solidify. Internal stress can be induced during solidification which arouses concerns of safety to heritages from material scientists and conservators.

In this work, the internal stress generated by the solidification of menthol melt, is studied by resistance strain gauge method. The results show that small organic molecules, like menthol, will generate certain amount of stress on the objects upon solidification due to volumetric shrinkage. The magnitudes of the strain and stress are affected by the amount and the temperature of melt 
applied. For very delicate relics, less and cooler melts should be considered in order to reduce stress.

Detailed studies on three different substrates further show that the nature of the stress is not always compression. For porous objects, which are very commonly observed on an excavation sites, tensile stress may also occur. Meanwhile, the stress can be transmitted to neighboring areas other than the area where the melt is applied, especially in flexible objects. Thus, special attention should be given to relics like paper, fabrics etc.

Overall, such internal stress is generally quite small. On-site temporary consolidation using melted menthol is quite safe to fragile cultural heritages. For the past a few years, nearly 2000 pieces have been consolidated and extracted during excavations using menthol in China.

\section{Supplementary information}

Supplementary information accompanies this paper at https://doi. org/10.1186/s40494-020-00414-y.

Additional file 1. Supporting information.

\section{Abbreviation}

CDD: Cyclododecane.

\section{Acknowledgements}

The authors are grateful to the financial supports from the National Key Research and Development Program of China (No. 2019YFC1520104, 2019YFC1520504), Key Program of National Natural Science Foundation of China (No. 51732008), Natural Science Foundation of China (No. 11672170) and Shanghai University.

\section{Authors' contributions}

$X C$ : conducted most of the experiments and data analyses, wrote the initial draft of this manuscript; $Y X$ : implemented the strain gauge experiments and data analyses; MC: implemented the strain gauge experiments; $\mathrm{XH}$ : conceptualized the research, interpreted data and finalized the manuscript; $\mathrm{HL}$ : helped to design the experiment setup, revised the manuscript; YS: improved the experiment setup, interpreted the data and revised the manuscript. All authors read and approved the final manuscript.

\section{Funding}

The research is funded by National Key Research and Development Program of China, Key Program of National Natural Science Foundation of China, Natural Science Foundation of China and Shanghai University.

\section{Availability of data and materials}

All data analyzed during this study are included in this published article. Raw data are available upon request.

\section{Competing interests}

The authors declare that they have no known competing financial interests or personal relationships that could have appeared to influence the work reported in this paper.

\section{Author details}

1 School of Materials Science and Engineering, Shanghai University, Shanghai 200444, China. ${ }^{2}$ Institute for the Conservation of Cultural Heritage, Shanghai University, Shanghai 200444, China. ${ }^{3}$ School of Mechanics and Engineering Science, Shanghai University, Shanghai 200444, China.
Received: 17 March 2020 Accepted: 1 July 2020

Published online: 09 July 2020

\section{References}

1. Ashour T, Wieland $\mathrm{H}$, Georg $\mathrm{H}$. The influence of natural reinforcement fibres on insulation values of earth plaster for straw bale buildings. Mater Des. 2010;31(10):4676-85.

2. Al-Rifaie WN, Al-Niami M. Mechanical performance of date palm fibrereinforced gypsums. Innov Infrastruct Solut. 2016;1(1):18.

3. Khenfer MM, Morlier PP. Cellulose fibres reinforced plaster. Mater Struct. 1999;32(215):52-8.

4. Altin S, Anil O, Kopraman Y, Belgin C. Strengthening masonry infill walls with reinforced plaster. Proc Inst Civil Eng Struct Build. 2010;163(5):331-42

5. Quagliarini E, D'Orazio M. Light vaults with frescoes or stuccoes strengthened by glass fiber-reinforced polymer (GFRP) the role of the reinforcement on intrados strains: first experimental data. Int J Archit Herit. 2010:4(4):320-36

6. Lorenzini RG, Kline WM, Wang CC, et al. The rational design of polyurea \& polyurethane dielectric materials. Polymer. 2013;54(14):3529-33.

7. Defeyt C, Langenbacher J, Rivenc R. Polyurethane coatings used in twentieth century outdoor painted sculptures. Part I: comparative study of various systems by means of ATR-FTIR spectroscopy. Herit Sci. 2017;5:11.

8. Defeyt $C$, Schilling $M$, Langenbacher J. Polyurethane coatings in twentieth century outdoor painted sculptures. Part II: comparative study of four systems by means of Py-GC/MS. Herit Sci. 2017;5:15.

9. Chaudhuri H, Karak N. Water dispersed bio-derived transparent polyurethane: synthesis, properties including chemical resistance, UV-aging, and biodegradability. Prog Org Coat. 2020;146:105730.

10. Su BM, Zhang HB, Zhang BJ, Jiang DQ, Zhang R, Tan X. A scientific investigation of five polymeric materials used in the conservation of murals in Dunhuang Mogao Grottoes. J Cult Herit. 2018;31:105-11.

11. Cocca M, D'Arienzo L, D'Orazio L, Gentile G, Mancarella C, Martuscelli E, Polcaro C. Water dispersed polymers for textile conservation: a molecular, thermal, structural, mechanical and optical characterisation. J Cult Herit. 2006;7(4):236-43.

12. Briffa SM, Vella DA. The behaviour of as-applied and artificially weathered silica-epoxy consolidants on a typical Mediterranean porous limestone: a comparison with TEOS. Herit Sci. 2019;7:30.

13. Formia A, Tulliani JM, Antonaci P, Sangermano M. Epoxy monomers consolidant for lime plaster cured via a redox activated cationic polymerization. J Cult Herit. 2014;15(6):595-601.

14. Brown M, Davidson A. The use of cyclododecane to protect delicate fossils during transportation. J Vertebr Paleontol. 2010;30(1):300-3.

15. Sophie R, Christina R. The uses of cyclododecane in conservation. Stud Conserv. 2008;53:17-31.

16. Stein R, Kimmel J, Marincola M, Klemm F. Observations on cyclododecane as a temporary consolidant for stone. J Am Inst Conserv. 2000;39(3):355-69.

17. Bruckle I, Thornton J, Nichols K, Strickler G. Cyclododecane: technical note on some uses in paper and objects conservation. J Am Inst Conserv. 1999;38(2):162-75.

18. Munoz-Vinas S, Vivancos-Ramon V, Ruiz-Segura P. The influence of temperature on the application of cyclododecane in paper conservation. Restaur-Int J Preserv Libr Arch Mater. 2016:37(1):29-48.

19. Diaz-Marin C, Aura-Castro E, Sanchez-Belenguer C, Vendrell-Vidal E. Cyclododecane as opacifier for digitalization of archaeological glass. J Cult Herit. 2016;17:131-40.

20. Maish JP, Risser E. A case study in the sue of cyclododecane and latex rubber in the molding of marble. J Am Inst Conserv. 2002;41(2):127-37.

21. Vernez D, Wognin B, Tomicic C, Plateel G, Charriere N, Bruhin S. Cyclododecane exposure in the field of conservation and restoration of art objects. Int Arch Occup Environ Health. 2011;84(4):371-4.

22. Yu Y, Zhang W, Han X. Menthol-based eutectic mixtures: novel potential temporary consolidants for archaeological excavation applications. J Cult Herit. 2019;39:103-9.

23. Han X, Rong B, Huang X, Zhou T, Luo H, Wang C. The use of menthol as temporary consolidant in the excavation of Qin Shihuang's Terracotta army. Archaeometry. 2014;56(6):1041-53. 
24. Han X, Huang X, Zhang BJ. Laboratory research into the use of menthol as a temporary consolidant for conservation on archaeological excavations. Archaeometry. 2018;60(6):1334-45.

25. Sadek H, Berri BH, Weiss RG. Sublimable layers for protection of painted pottery during desalination. A comparative study. J Am Inst Conserv. 2018;57(4):189-202

26. Roos YH, Karel M, Labuza TP. Melting and crystallization of sugars in highsolids systems. J Agric Food Chem. 2013;61(13):3167-78.

27. Berto F, Lazzarin P. Recent developments in brittle and quasi-brittle failure assessment of engineering materials by means of local approaches. Mater Sci Eng. 2014;75:1-48.

28. Abadias G, Chason E, Keckes J, Sebastiani M, Thompson GB, Barthel E, Doll GL, Murray CE, Stoessel CH, Martinu L. Stress in thin films and coatings: current status, challenges, and prospects. J Vac Sci Technol A Vac Surf Films. 2018;36(2):020801.

29. Van Leeuwen M, Kamminga JD, Mittemeijer EJ. Diffraction stress analysis of thin films: modeling and experimental evaluation of elastic constants and grain interaction. J Appl Phys. 1999:86:1904-14.

30. Holden TM, Root JH, Holt RA. Neutron-diffraction measurements of stress. Phys B. 1995:213-214:793-6.

31. Bemporada E, Brisottob M, Deperob LE, Gelfib M, Korsunskyc AM, Luntc AJG, Sebastiania M. A critical comparison between XRD and FIB residual stress measurement techniques in thin films. Thin Solid Films. 2014;572:224-31.

32. Grabner L. Spectroscopic technique for the measurement of residual stress in sintered $\mathrm{Al}_{2} \mathrm{O}_{3}$. J Appl Phys. 1978;49:580-3.

33. Parnas L, Bilir ÖG, Tezcan E. Strain gage methods for measurements of opening mode stress intensity factor. Eng Fract Mech. 1996;55(3):485-92.
34. Zike S, Mikkelsen LP. Correction of gauge factor for strain gauges used in polymer composite testing. Exp Mech. 2013;54(3):393-403.

35. Teomete $\mathrm{E}$. The effect of temperature and moisture on electrical resistance, strain sensitivity and crack sensitivity of steel fiber reinforced smart cement composite. Smart Mater Struct. 2016;25(7):075024.

36. Freddi A, Olmi G, Cristofolini L. Introduction to the application of strain gages. Exp Stress Anal Mater Struct. 2015;4:23-100.

37. Liu GZ, Liu H, Wei AQ. A new device for stress monitoring in continuously welded rails using bi-directional strain method. J Mod Transp. 2018;26(3):179-88.

38. Hu XY, Wang BW, Ji H. A wireless sensor network-based structural health monitoring system for highway bridges. Comput Aided Civil Infrastruct Eng. 2013;28(3):193-209.

39. Tegtmeier FL. Strain gauge based microsensor for stress analysis in building structures. Measurement. 2008;41(10):1144-51.

40. Teomete E, Kocyigit OI. Tensile strain sensitivity of steel fiber reinforced cement matrix composites tested by split tensile test. Constr Build Mater. 2013;47:962-8.

41. Afonin GV, Mitrofanov YP, Kobelev NP, Pinto MWD, Wilde G, Khonik VA Relationship between the enthalpies of structural relaxation, crystallization and melting in metallic glass-forming systems. Scripta Mater. 2019;166:6-9.

\section{Publisher's Note}

Springer Nature remains neutral with regard to jurisdictional claims in published maps and institutional affiliations.

\section{Submit your manuscript to a SpringerOpen ${ }^{\circ}$ journal and benefit from:}

- Convenient online submission

- Rigorous peer review

- Open access: articles freely available online

- High visibility within the field

- Retaining the copyright to your article

Submit your next manuscript at springeropen.com 